\title{
CARACTERÍSTICAS FENOTÍPICAS DO NANISMO EM PÔNEIS NEONATOS: RELATO DE CASOS
}

\author{
PHENOTYPIC FINDINGS OF DWARFISM IN NEWBORN PONY: CASES REPORT
}

\author{
M. J. WATANABE ${ }^{1}$, J. M. ALONSO ${ }^{2}$, A. L. M. YAMADA ${ }^{2}$, K. A. RODRIGUES ${ }^{3}$, \\ C. A. HUSSNI ${ }^{4}$, A. L. G. ALVES ${ }^{4}$
}

\section{RESUMO}

Foram atendidos no Hospital Veterinário, três neonatos com características fenotípicas de nanismo, sendo dois MiniHorses e um Pônei Brasileiro. Os animais apresentavam desproporcionalidade craniana, defeito de oclusão dentária e alterações osteo-musculares compatíveis com a anormalidade, como a deformação dos ossos metatarsianos e membros desproporcionalmente curtos. Ao exame radiográfico foram identificadas alterações fisárias de côndilos femorais e em epífise proximal dos terceiros ossos metatarsianos. Devido à elevada possibilidade de futuras complicações e perda da qualidade de vida, os animais foram submetidos à eutanásia. Ressalta-se a importância da divulgação e reconhecimento das alterações fenotípicas relacionadas como o nanismo em equinos, possibilitando que o diagnóstico possa direcionar os cruzamentos para a não transmissão desta anormalidade como herança genética.

PALAVRAS-CHAVE: Deformidade de membros. Mini-horse. Osteocondrodisplasia. Pônei. Prognatismo.

\section{SUMMARY}

Three newborn Mini-Horses and one Brazilian Pony horses were presented to the Veterinary Hospital with phenotypic appearance of dwarfism. They had relatively larger head conformation, occlusive dental defect and musculoskeletal changes such as abnormal short limbs and deformation on the third metatarsal bone. The radiographic examination showed abnormal growth plates on femoral condyle and proximal thirds metatarsal bones. Due to the high possibility of future complications and quality of life loss, the animals were euthanized. We emphasize the importance of recognition of phenotypic changes related to dwarfism in horses, enabling the phenotypic diagnosis can direct crossings for nontransmission of this abnormality as genetic inheritance.

KEY-WORDS: Limb deformity. Miniature horse. Ostochondrodysplastic. Pprognathism.

\footnotetext{
${ }^{1}$ Prof. Doutor do Departamento de Cirurgia e Anestesiologia Veterinária. Faculdade de Medicina Veterinária e Zootecnia- FMVZUNESP - Botucatu. Autor para correspondência: E-mail: watanabe@fmvz.unesp.br DCAV - FMVZ - UNESP - Botucatu. Distrito de Rubião Júnior s/n Caixa Postal 560. Cep: 18618-970 Botucatu - SP - Brasil.

${ }^{2}$ Doutoranda do Departamento de Cirurgia e Anestesiologia Veterinária. Faculdade de Medicina Veterinária e Zootecnia- FMVZUNESP, Botucatu- SP, Brasil.

${ }^{3}$ Mestranda do Departamento de Cirurgia e Anestesiologia Veterinária. Faculdade de Medicina Veterinária e Zootecnia- FMVZUNESP, Botucatu- SP, Brasil.

${ }^{4}$ Prof. Adjunto do Departamento de Cirurgia e Anestesiologia Veterinária. Faculdade de Medicina Veterinária e Zootecnia- FMVZUNESP, Botucatu- SP, Brasil.
} 
Pôneis são equinos de baixa estatura, cuja altura de cernelha é inferior a $150 \mathrm{~cm}$, sendo encontradas mais de 100 raças criadas no mundo. No Brasil, destaca-se a raça Pônei Brasileiro, com padrão racial de altura máxima de cernelha de $100 \mathrm{~cm}$ para machos e $110 \mathrm{~cm}$ para fêmeas (ABCCPONEI, 2013) e a raça Mini-Horse com $93 \mathrm{~cm}$ para machos e $98 \mathrm{~cm}$ para fêmeas (ABCMH, 2013). A pequena estatura destes animais é decorrente do efeito cumulativo da seleção genética e cruzamentos entre os animais mais baixos (MARTINEZ et al., 2007; THOMPSON, 2007).

O nanismo é definido como uma forma de desenvolvimento anormal, descrita nos homens e em alguns animais, porém pouco reportada em equinos (MARTINEZ et al., 2007; THOMPSON, 2007). É determinado por genes que além de contribuírem para uma pequena estatura, podem interferir negativamente na saúde e reprodução (EBERTH et al., 2009). Objetivou-se com este estudo, descrever as características fenotípicas congênitas de pôneis neonatos portadores de nanismo.

Foram atendidos no Hospital Veterinário FMVZ, três pôneis neonatos, sendo um macho (caso 1) e uma fêmea (caso 2) da raça Mini-Horse, respectivamente atendidos no ano de 2008 e 2010 e uma fêmea (caso 3) da raça Pônei Brasileiro, atendida em 2011. Todos os animais foram atendidos no primeiro dia de vida, com a queixa de má formação dos membros e dificuldade de amamentação. Todos os potros foram oriundos de gestação a termo, em éguas com escore corporal dentro da normalidade e sem histórico de vacinação. Negou-se consanguinidade, e foram relatados cruzamentos prévios de seus progenitores cujos produtos não apresentaram anormalidades de desenvolvimento.

Ao exame clínico foram verificadas alterações das proporções cranianas, prognatismo, olhos desproporcionalmente grandes e protuberantes além das deformidades e desvios dos membros (Figura 1). No caso 1, observou-se deformidade angular do tipo varus carpiano, flacidez articular metacarpo $\mathrm{e}$ metatarsofalângica, hiperextensão carpiana bilateral, lordose, desvio dorsal dos metatarsianos na região proximal dos membros pélvicos, resultando em posição semelhante ao "apoio de coelho"), incapacidade de manter-se em posição quadrupedal e opacidade do cristalino. No caso 2, observou-se valgus carpiano, hiperextensão das articulações metacarpofalângicas com apoio na região palmar das articulações interfalângicas, desvio dorsal dos metatarsianos na região proximal, dificuldade para locomoção manutenção em posição quadrupedal e para ingestão de leite. No caso 3, observou-se varus carpiano, moderada hiperextensão das articulações metacarpofalângicas, desvio dorsal dos metatarsianos na região proximal, dificuldade de locomoção e de manter-se em posição quadrupedal.

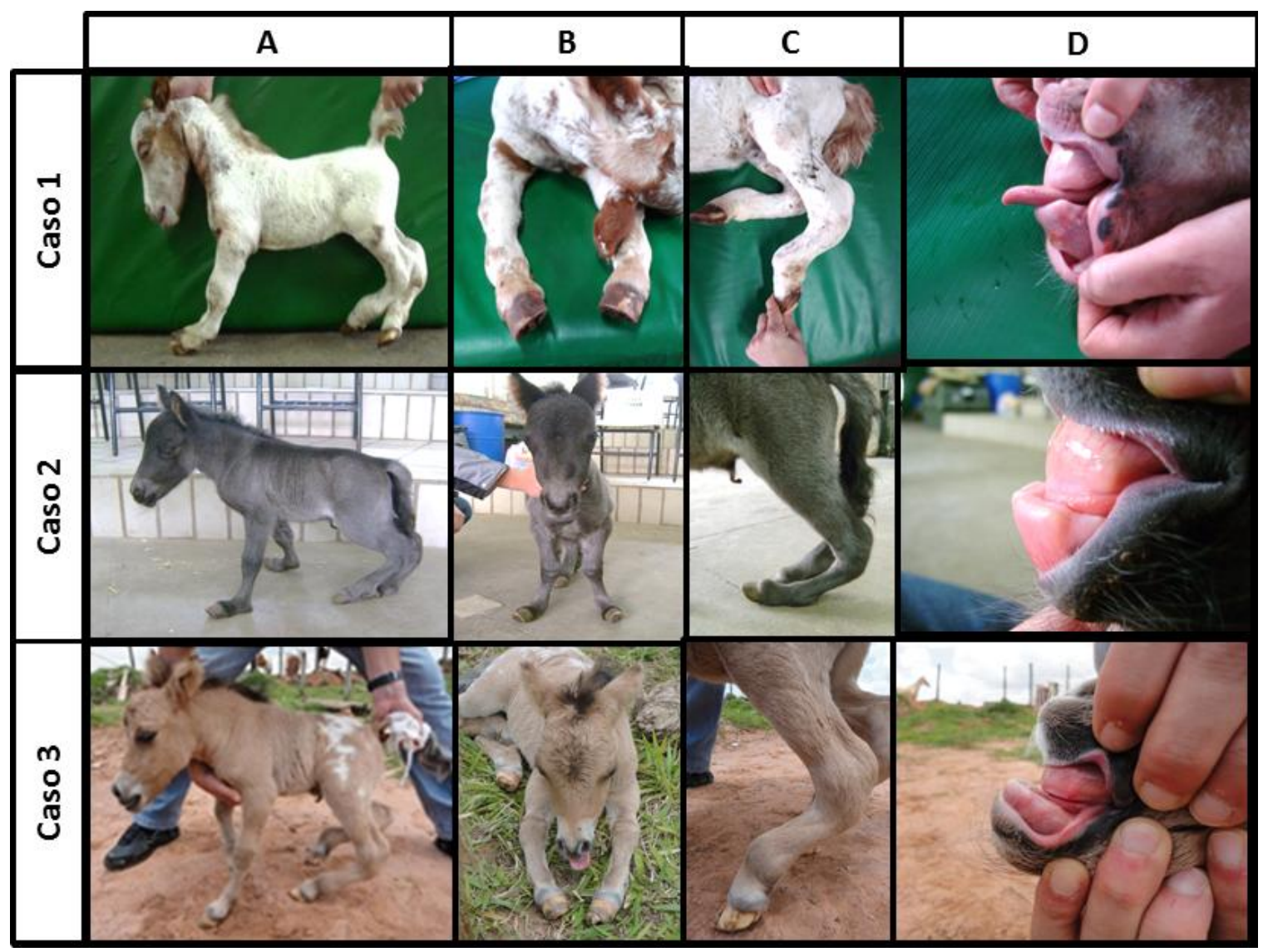

Figura 01: Achados fenotípicos do nanismo em Mini-Horses e Pônei (casos 1, 2 e 3). A : Vista lateral - deformidades dos membros (posição semelhante ao "apoio de coelho"). B: Vista frontal - deformidades angulares do tipo varus carpiano (caso 1 e 3) e valgus carpiano (caso 2). C: Vista lateral do membro pélvico - deformação da região proximal do III metatarsiano. D: Vista lateral da região rostral da mandíbula e maxila - prognatia. 

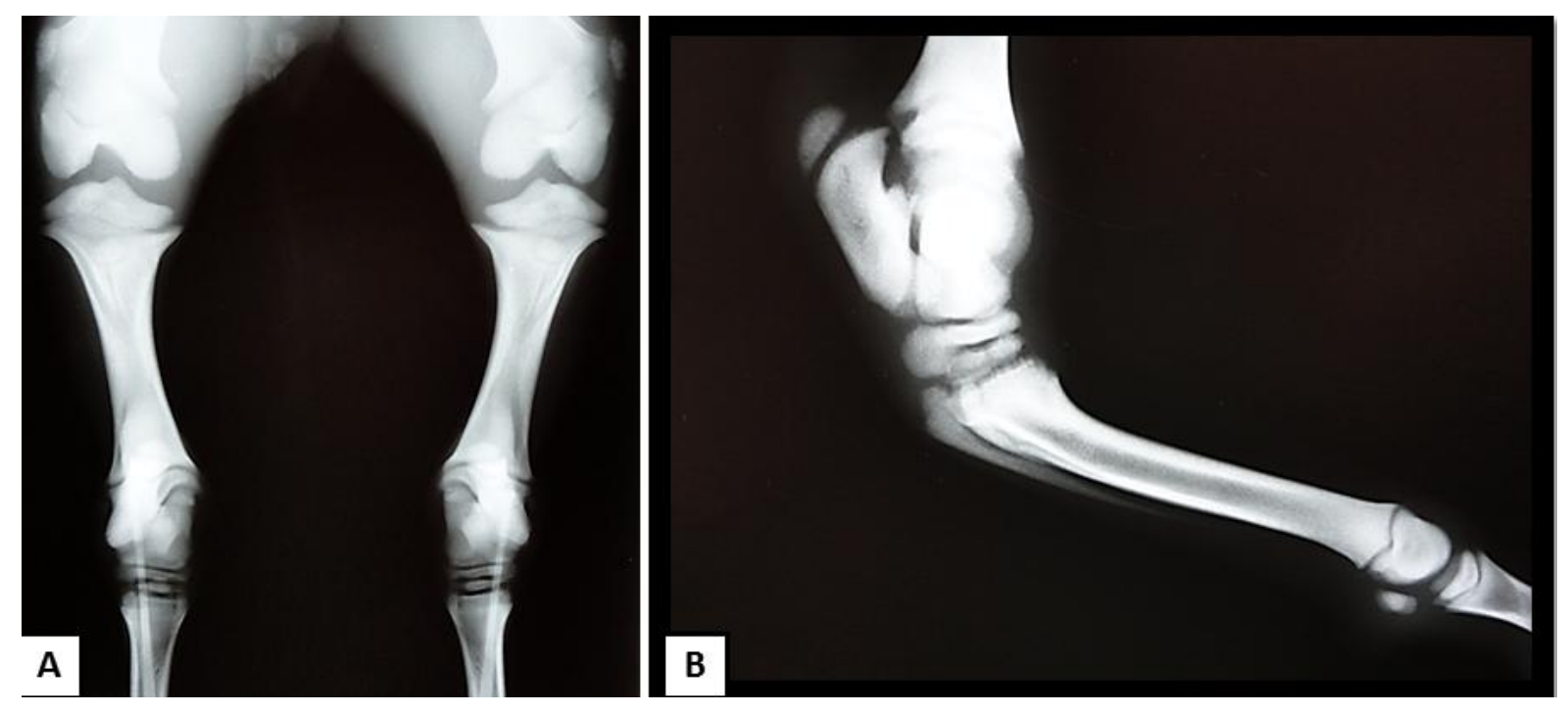

Figura 02 - Exame radiográfico do caso 2. A - Projeção crânio-caudal: irregularidade em epífise óssea dos côndilos femorais e terceiros ossos metatarsianos tanto do membro pélvico esquerdo quanto direito; B - Projeção látero-medial membro pélvico direito: Deformidade e desvio proximal dos ossos metatarsianos.

No caso 2, foi realizado o exame radiográfico dos membros pélvicos, em que onde se identificou deformidade e desvio da porção proximal dos ossos metatarsianos bilaterais, além de irregularidade em epífise óssea, predominantemente nos côndilos femorais e em epífise cranial dos terceiros ossos metatarsianos (Figura 2), compatível com a displasia metafisária de ossos metacarpianos e metatarsianos descrita em equinos acometidos por nanismo (BACK et al., 2008).

Devido às alterações fenotípicas observadas nos três casos, os neonatos foram diagnosticados portadores de nanismo. O diagnóstico foi baseado na descrição de BACK et al. (2008), que referem como as principais alterações observadas nos animais afetados, o retardo do crescimento fisário de membros e costelas, e o crescimento mais rápido da cabeça e do tronco em relação às demais regiões. Ainda, associaram-se como proposta diagnóstica as variações fenotípicas previamente descritas: anormalidades cranianas tais como cabeça desproporcionalmente grande, olhos e órbitas grandes e protuberantes, proporção maior da região frontal em relação à nasal, alterações na oclusão dentária e estreitamento de vias aéreas (BACK et al., 2008; EBERTH et al., 2009); encurtamento e deformidades dos membros, ocasionando restrição na flexão ou extensão e articulações com aumento de volume (BACK et al., 2008; EBERTH et al., 2009); hiperextensão das articulações metacarpo e/ou metatarsofalângicas (BACK et al., 2008; GUSSEKLOO et al., 2011); baixa estatura desproporcional (EBERTH et al., 2009); deformações progressivas nos cascos e desenvolvimento de artrites, devido à má formação dos membros (EBERTH et al., 2009); alterações na coluna vertebral que podem aparecer tardiamente (EBERTH et al., 2009); tórax mais largo com estreitamento na junção costocondral (BACK et al., 2008).

Considerou-se em todos os casos a elevada probabilidade da ocorrência de complicações futuras decorrentes das diversas más formações observadas, como artropatias, deformação dos cascos (EBERTH et al., 2009), e dificuldade de alimentação, optando-se pela eutanásia. Entretanto, não existem, informações científicas quanto ao prognóstico do nanismo caso sejam realizados os tratamentos para a as deformidades dos membros, uma vez que, no período pós-natal não são verificadas complicações restritivas à vida, e caso seja adotado um manejo de suporte alimentar, haveria uma expectativa por parte de proprietários e profissionais de estratégias terapêuticas para não se optar pela eutanásia.

Deve-se ponderar a informação por parte de criadores e profissionais da ocorrência ser frequente, visto terem sido atendidos 3 casos em um período de observação de 4 anos , Entretanto, acredita-se que por vezes o nanismo não seja diagnosticado ou divulgado para não denegrir a qualidade dos animais produzidos. Estudos são necessários junto às associações de criadores visando- se verificar a real incidência com base em dados oficiais, controlando-se assim, a disseminação dos genes dessa anormalidade. Como exemplo, a Associação Americana de Miniature Horse criou uma resolução proibindo o registro de animais que apresentam duas ou mais características relacionadas com o nanismo (HATFIELD et al., 2007; BACK et al., 2008).

Os três casos relatados referiram-se a potros das raças Pônei Brasileiro e Mini-Horse, sendo que são escassos os estudos visando à descrição e etiologia do nanismo nas diversas raças, limitando-se a Friesian (BACK et al., 2008, GRAAF-ROELFSEMA et al., 2009; ORR et al., 2010; GUSSEKLOO et al., 2011). Há uma descrição em pônei Shetland e em um potro da raça Miniature Horse de 5 meses de idade com anormalidades do trato respiratório anterior, diagnosticadas após complicações de procedimento anestésico HATFIELD et al. (2007).

O mecanismo desencadeante deste distúrbio de crescimento ainda foi pouco estudado na espécie 
equina, mas acredita-se que o nanismo esteja relacionado com uma herança genética recessiva (BACK et al., 2008), não sendo observada diferença nos níveis de hormônio do crescimento entre potros Friesian normais e com nanismo (GRAAFROELFSEMA et al., 2009). Com o intuito de realizar o mapeamento do determinante genético, ORR et al. (2011), compararam 10 cavalos Friesian com nanismo a 10 normais identificando-se a suposta região de localização do gene determinante do nanismo nesta raça.

Assim, até que o diagnóstico por análise do genoma seja viável, salienta-se a importância da divulgação e reconhecimento das alterações fenotípicas relacionadas com o nanismo em equinos, possibilitando que a identificação morfológica possa direcionar os cruzamentos para a não transmissão desta anormalidade como herança genética.

\section{REFERENCIAS}

ABCCPONEI - Associação Brasileira dos Criadores do Cavalo Pônei. Padrão racial. Disponível em <http://www.abccponei.org.br>. Acesso em: julho de 2013.

ABCMH - Associação Brasileira dos Criadores MiniHorse. Regulamento - Padrão racial. Disponível em <http://www.ponei.com.br/>. Acesso em julho de 2013.

BACK, W.; VAN DER LUGT, J. J.; NIKKELS, P. G.; VAN DEN BELT, A. J.; VAN DER KOLK, J. H.; STOUT, T.A. Phenotypic diagnosis of dwarfism in six Friesian horses. Equine Veterinary Journal, v.40, n.3, p. 282-287, 2008. Disponível em < http://onlinelibrary.wiley.com/doi/10.2746/042516408 X278201/pdf > Acesso em 25 Jul. 2013. doi: 10.2746/042516408X278201.

DE GRAAF-ROELFSEMA, E.; BACK, W.; KEIZER, H. A.; STOUT, T. A.; VAN DER KOLK, J. H. Normal function of the hypothalamic-pituitary growth axis in three dwarf Friesian foals. Veterinary Record, v.165, n.13, p.373-376, 2009. Disponível em < http://veterinaryrecord.bmj.com/content/165/13/373.ab stract > Acesso em 25 Jul. 2013. doi: doi:10.1136/vr.165.13.373
EBERTH, J.; SWERCZAK, T.; BAILEY, E. Investigation of Dwarfism Among Miniature Horses using the Illumina Horse SNP50 Bead Chip. Journal of Equine Veterinary Science, v.29, p.315, 2009. Disponível em <http://www.j-evs.com/article/S07370806(09)00286-X/fulltext > Acesso em 25 Jul. 2013.doi:10.1016/j.jevs.2009.04.021

GUSSEKLOO, S. W.; LANKESTER, J.; KERSTEN, W.; BACK, W. Effect of differences in tendon properties on functionality of the passive stay apparatus in horses. American Journal of Veterinary Research, v.72, n.4, p.474-483, 2011. Disponível em < http://avmajournals.avma.org/doi/full/10.2460/ajvr.72. $4.474>$ Acesso em 25 Jul. 2013. doi: 10.2460/ajvr.72.4.474

HATFIELD, C. L.; RILEY, C. B. Management of airway difficulties during induction of general anesthesia in an American miniature horse with dwarfism. Canadian Veterinary Journal .v.48, p.188191, 2007. Disponível em < http://www.ncbi.nlm.nih.gov/pmc/articles/PMC178023 8/ > Acesso em 25 Jul. 2013.

MARTÍNEZ, S.; FAJARDO, R.; VALDÉS, J.; ULLOA-ARVIZU, R.; ALONSO, R. Histopathologic study of long-bone growth plates confirms the basset hound as an osteochondrodysplastic breed. Canadian. Journal of Veterinary Research, v. 71, p. 66-69, 2007. Disponível em < http://www.ncbi.nlm.nih.gov/ pmc/articles/PMC1635992/ > Acesso em 25 Jul. 2013.

THOMPSON, K. Bones and joints. In: Maxie M.G. (ed) Jubb, Kennedy, and Palmer's Pathology of Domestic Animals, $5^{\circ}$ ed., Saunders Elsevier, p.24-33, 2007. 